\title{
Implementation of STEM Education in Learning Cycle 5E to Improve Concept Understanding On Direct Current Concept
}

\author{
Dewi Susanti Kaniawati \\ Postgraduate School Indonesia University of Education \\ Indonesia University of Education \\ Bandung, Indonesia \\ dewi_suryadi@ymail.com
}

\author{
Ida Kaniawati \\ Postgraduate School Indonesia University of Education \\ Indonesia University of Education \\ Bandung, Indonesia \\ kaniawati@upi.edu
}

\author{
Irma Rahma Suwarma \\ Postgraduate School Indonesia University of Education \\ Indonesia University of Indonesia \\ Bandung, Indonesia \\ rahmai@ymail.com
}

\begin{abstract}
This study has been conducted to investigate the comparisons of concept understanding students who has been subjected Learning Cycle (LC) 5E teaching model combined with STEM and students who has been subjected LC 5E without STEM on direct current electricity concept. Implementation STEM in this research is apply and practice STEM content to integrate technology, engineering and mathematics. The quasi experiment methodology was used in this study. The research includes pretest-posttest control group design. The subjects of the research consist of 92 students at $10^{\text {th }}$ grade of one of high school existing in Kabupaten Majalengka. The data collection tools for the research are $\mathbf{2 0}$ multiple choice of concept understanding test with indicator interpreting, comparing, exemplying, explaining and inferring. As a result of the research, it was found that implementation STEM in Learning Cycle 5E in direct current electricity improvement of concept understanding of students who received LC $5 \mathrm{E}$ combined with STEM higher than students who had learning LC 5E without STEM.
\end{abstract}

Keywords-STEM Education; Learning Cycle 5E; Concept Understanding

\section{INTRODUCTION}

National Research Council [1] explains that the study of physics should be moved and focused on concept understanding. Winkel [2] defines the ability to understand

it as an ability to understand and use the concepts, rules and principles. Today in Indonesia in the field of education was achieve of $21^{\text {st }}$ century skills such as problem solving skills, critical thinking, creativity. This skills must be trained and familiarized appear in teaching and learning. Of course before being able to achieve $21^{\text {st }}$ century skills students must first be able to understand a concept as a whole. For that it is necessary the use of a variety of learning approaches that could facilitate increased students' concept understanding that other capabilities can be achieved.

The purpose of education and the development of quality education today must shift is not just looking for value and graduation requirements but have a broad understanding that was offset by the $21^{\text {st }}$ century skills Twenty First century is the century of technology. Therefore, the use of technology in learning is absolutely necessary. The Indonesian people liked and most widely used technology product, but we do not want to learn or less interested in mastering science and technology.

Based on these facts Indonesia should integrate aspects of the Science, Technology, Engineering and Mathematics (STEM) in teaching and learning in school to grow interest the Indonesian people to like and competence in science, technology, engineering and mathematics.

\section{A. STEM Education}

STEM stands for Science, Technology, Engineering and Mathematics. In Bybee [3] stated that the term STEM first recognized in the 1990s. At that time the office of the NSF (National Science Foundation) The United States uses the term as shorthand SMET Science Mathematics, Engineering and Technology, but an employee of NSF reported that SMET as SMUT in the pronunciation, so change into STEM. Thus the Indonesian context refers to the four STEM fields of science, technology, engineering and mathematics. 
According to Bybee [3] generally STEM approach is to apply and practice the basic content of STEM in their situation / find in life, to be literate STEM (STEM Literacy). STEM literacy refers to:

a. Knowledge, attitudes and skills of an individual to identify questions and issues in real life, and draws conclusions based on the facts concerning issues of STEM.

b. An understanding of the characteristics of an individual STEM discipline as a form of knowledge, inquiry and human design.

c. The sensitivity of an individual on how STEM forming material and intellectual culture of our environment

d. The desire of an individual to be bound in the issue of STEM and STEM bound up with the idea.

According Stohlmann [4] "The quality of the integration of STEM approach is essential to promote student success in the future. Integrating STEM is one way to connect and make learning relevant to students. "One model that fits in teaching students in direct current electric material is $5 \mathrm{E}$ learning cycle model. Rustaman et.al [5] states that one of the learning model based on constructivism and play a role in increasing the understanding of the concept is the learning cycle model (Learning Cycle). The approach is expected to strengthen STEM education every learning phase 5E. Application of Science, Technology, Engineering and Mathematics in Cycle 5E making phase can optimize both the student's concept understanding. By understanding the concept of a student is able to identify the procedure or the process of calculating the correct and incorrect and is able to represent and interpret the idea to provide a simple inductive and deductive reason, either orally, in writing or demonstrating. If the students understand physics concepts well, then these students will be able to bring the concept into forms other issues.

In this research, analysis system of flashlight used to explore of direct curent electricity concept. This is one of strategy in STEM education.

\section{B. Concept Understanding}

Concept understanding consists of two words, namely understanding and concept. According to the great dictionary Indonesiang got word is not the root of understanding means understanding correct or out completely. Therefore, understanding is a method or process to make someone understand right about something. Deep understanding of the capabilities of the problem and able to provide an explanation of the implied meaning that is understood by the person. This ability is usually obtained in the learning process. Someone said to understand the concept if the person understands and is able to explain with words alone. Although an understanding of basic capabilities, but it is very important master students. Students will not be able to think critically if it does not have the ability to understand
According to Bloom [6] understanding are at the second in the cognitive domain. Comprehension ability is the ability to understand a concept and understand it and then interpret the concept. According to Bloom Revised in Anderson, et.all [7] there are seven indicators that can be developed in the levels of the cognitive process of understanding (Understand). The understanding of the capabilities described as follows:

1) Interpreting, interpretation occurs when students are able to transform information from one form to another. Ability to interpret includes changes words into other words (eg paraphrasing), the image into words, words into images, figures into words, and the like.

2) Exemplifying, exemplifies occurs when students are able to give examples of the concepts or general principles. Exemplifying includes the process of identifying the fundamental characteristics of a concept or general principles and use these features to select or create a sample.

3) Classifying, grouping occurs when students know that something (example or specific events) included in a specific category (eg concept or principle). Grouping embraces the characteristics or relevant patterns, which matches the specific examples and concepts or general principles.

4) Summarizing, summarizes occurs when students are able to express a single sentence that represents information received or abstract theme.

5) Inferring, concluded include the discovery of patterns in a series of examples or events. Summing occurs when the student is able to summarize or abstract a concept or principle which consists of a series of examples or events to draw connections between the characteristics of the circuit examples or those events.

6) Comparing, comparing occurs when students discover the similarities and differences between two or more objects, events, ideas, problems, or situations.

7) Explaining, describes occurs when students are able to build and use the causal model of a system. This model can be derived from the theory, or based on research or experience. Detailed explanation includes the process of creating a causal model, which includes every major part in a system or any important event in the series of events, and the process of using the model to determine a change in one part of the system or in a series of relationships that affect changes in other parts.

\section{Relevant Research}

Research on the application of STEM approach has been widely studied by researchers abroad. The results obtained are many benefits derived from the application of STEM approach can improve learning outcomes, increase motivation to learn, and increase interest in science [8]. The application of STEM learning approach can also improve the innovation, creativity and problem solving. [9] Research in the application of the approach STEM in 
Learning Cycle 5E has not done much in my country. But there are some foreign researchers have conducted Past studies showed that the application of the approach STEM in Learning Cycle 5E improved learning outcomes, liveliness and creativity of students : (1) Dona Clem [10] did research 5E Model Use For elementary STEM Education on the concept of pendulum swings, the result is an increase in students' creativity; (2) Sevil Ceylan [11] researched Improving A Sample Lesson Plan For Secondary Within The STEM (By Model 5E) on Chemistry subject matter, result there was an increased level of understanding of the concept of the student; (3) Pradeep M Dass [12] did STEM Teaching Effectively With The Learning Cycle Approach to the concept of Population Growth (Biology), the results Students are an increased level of understanding of the concept. The purpose of this study is to identify whether there are significant differences concept understanding inprovement between students who received LC 5E combined with STEM higher than students who had learning LC 5E without STEM

\section{RESEARCH METHOD}

\section{A. Research Method and Design}

In this research used quasy-experimental method. Research design used pretest-posttest control group design. Population in this study were all students of $10^{\text {th }}$ grade in one of senior high school in Majalengka city. As for the sample in this study were selected using cluster random sampling technique. Involved 92 students were choosen as participant devided in experiment class who taught LC 5E with STEM and in control class who taugh without STEM. The research conduct for five times teaching and learning process in class.

The instrument of data collection concept understanding was multiple test choice format . The test included 20 items developed by researcher by considering the related literature.. Students given twice test of concept understanding for pretest and posttest with same instrument. Instrument test has been judgement by expert. After data collected, quantity of students' concept understanding by calculating the average $\mathrm{N}$-gain.

\section{RESULTS AND DISCUSSION}

\section{A. Result}

TABLE I. DESCRIPTION OF SCORE OF CONCEPT UNDERSTANDING

\begin{tabular}{|c|c|c|c|c|c|c|}
\hline & \multicolumn{3}{|c|}{ Experiment Class } & \multicolumn{3}{c|}{ Control Class } \\
\cline { 2 - 7 } & $\begin{array}{c}\text { Pretes } \\
\mathbf{t}\end{array}$ & $\begin{array}{c}\text { Posttes } \\
\mathbf{t}\end{array}$ & $\langle g\rangle$ & Pretest & $\begin{array}{c}\text { Posttes } \\
\mathbf{t}\end{array}$ & $\langle g\rangle$ \\
\hline $\begin{array}{c}\text { Number of } \\
\text { Student }\end{array}$ & 46 & 46 & 46 & 46 & 46 & 46 \\
\hline Average & 30,1 & 70,8 & 0,58 & 30,0 & 65,3 & 0,49 \\
\hline $\begin{array}{c}\text { Standar } \\
\text { deviation }\end{array}$ & 7,9 & 12,1 & 17,05 & 7,0 & 9,9 & 16,34 \\
\hline
\end{tabular}

Table 1 shows that the students' concept understanding increased in experimentl class better than the control class. Based on the acquisition score pretest, posttest and N-gain $(<\mathrm{g}\rangle)$ understanding of concepts in table 1 , it is known that the average score of students' pretest experimental class of 30.1 (30\% of the ideal score), while the average score of the pretest control class is 30,0 (30\% of the ideal score), while the average score of the posttest experiment class $70,8(71 \%)$ and the control class is $65.3(65.0 \%)$. Thus, students in the experiment class increased the average score $\mathrm{N}$-gain was 0.58 and increased the average score of control class 0,49 . On average the experimental class and control class medium category. This shows that the students' understanding of the concept after attending education in general has increased in the experiment class in which students have a better understanding of the concepts than students in the control class.

To see if there are significant differences in improving concept understanding between the experimental class and control class then performed a statistical analysis

\section{1) Normalitas Test} II.

Normalitas Test for concept understanding test in Tabel

TABLE II. NORMALLY TEST N-GAIN

\begin{tabular}{|c|c|c|c|}
\hline Data Source & Class & Sig. & Conclude \\
\hline \multirow{2}{*}{ N-gain } & Ekperiment & 0,493 & Normal \\
\cline { 2 - 4 } & Kontrol & 0,510 & Normal \\
\hline
\end{tabular}

Table II shows that the normality test results $\mathrm{N}$-gain understanding of the concept of data-grade students experiment and control group gained significance $>0.05$. It can be concluded that the N-gain Data understanding of the concept of direct current both classes of normally distributed.

2) Homogeneity Test

Homogeneity test $\mathrm{N}$-gain are presented in Table III.

TABLE III. HOMOGENEITY TEST N-GAIN

\begin{tabular}{|c|c|c|c|}
\hline Data & $\mathbf{F}_{\text {coumt }}$ & $\mathbf{F}_{\text {table }}$ & Conclude \\
\hline N-gain & 1,04 & 1,63 & Homogen \\
\hline
\end{tabular}

From Table III it can be seen that $\mathrm{F}_{\text {count }}<\mathrm{F}_{\text {table }}$ thus concluded that the data $\mathrm{N}$-gain experimental class and control class is homogeneous. Furthermore, the parametric statistical tests (t-test).

\section{3) $T$ Test}

This test is intended to see the difference between two average scores increase students' understanding of concepts between the experiment class and class control. Testing using t-test can be seen in Table IV.

TABLE IV. T TEST N-GAIN IN BOTH CLASS

\begin{tabular}{|c|c|c|c|c|c|}
\hline Data & Class & Average & $\begin{array}{c}\text { Std. } \\
\text { Dev }\end{array}$ & t-tes & $\begin{array}{c}\text { Sig* (2- } \\
\text { tailed) }\end{array}$ \\
\hline \multirow{2}{*}{ N-gain } & Experiment & 0,58 & 0,17 & 2,81 & 0,007 \\
\cline { 2 - 4 } & control & 0,49 & 0,16 & & \\
\hline
\end{tabular}


Research hypothesis test is done by using t-test one tile. Based on data processing is done, the result $\mathrm{t}_{\text {count }}$ and $\mathrm{t}_{\text {table }}$ as shown in Table V.

TABLE V. HYPOTHESIS TEST

\begin{tabular}{|c|c|c|}
\hline $\mathbf{t}_{\text {hitung }}$ & $\mathbf{t}_{\text {tabel }}$ & Conclude \\
\hline 2,81 & 1,66 & $\mathrm{H}_{0}$ rejected \\
\hline
\end{tabular}

After processing the data obtained $t_{\text {count }}$ and $t_{\text {table }}$ with 2.81 and 1.66 for 90 degrees of freedom $(\mathrm{df}=\mathrm{n} 1+\mathrm{n} 2-2=$ $32+33-2=90)$ and the confidence level of 0.95 . Obtaining this $\mathrm{t}_{\text {table }}<\mathrm{t}_{\text {count }}$ and further define the research hypotheses are proving their significance to the concept understanding in the LC 5E STEM class compared to LC 5E learning model without STEM. Based on Table 5 can be seen that $t$ count $>\mathrm{t}$ table value by level trust 0.95 . From these results it can be stated that the null hypothesis $\left(\mathrm{H}_{0}\right)$ is rejected, which means that the alternative hypothesis (Ha) is accepted. Therefore, it can be concluded that significant STEM approach to LC 5E can further enhance students' concept understanding compared LC 5E learning model without STEM.

Increased understanding of the concept can be analyzed on a classification indicator of understanding of the concept is the ability to interpret, pointed, inferring, comparing, and explaining. The way is by first classifying data based on indicators of understanding. Value average of $\mathrm{N}$-gain is based on indicators of understanding of the concept for the experiment group demonstrated Table VI.

TABLE VI. AVERAGE N-GAIN EACH OF INDICATOR UNDERSTANDING

\begin{tabular}{|l|c|c|}
\hline $\begin{array}{c}\text { Indicator of } \\
\text { Understanding }\end{array}$ & $\begin{array}{c}<\mathrm{g}>\text { Experiment } \\
\text { Class }\end{array}$ & $\begin{array}{c}<\mathrm{g}>\text { Control } \\
\text { Class }\end{array}$ \\
\hline Interpreting & 0,56 & 0,44 \\
\hline Exemplying & 0,88 & 0,75 \\
\hline Inferring & 0,72 & 0,66 \\
\hline Comparing & 0,51 & 0,44 \\
\hline Expalining & 0,38 & 0,31 \\
\hline
\end{tabular}

Table VI showed that the average value $\mathrm{N}$-gain for each indicator experimental class students concept understanding is higher than students in the control class. The experimental class indicator of understanding has an average value $\mathrm{N}$-gain is highest indicator of 0.88 exemplifies the high category, while the lowest is explained by 0.38 indicator with the medium category. So is the case in the control class has an average value of $\mathrm{N}$-gain higher indicator of 0.75 exemplying the concept of understanding with high category and indicator explaining was the lowest at 0.31 which explains the low category. If we look at Table VI. comparison of $\mathrm{N}$-gain each indicator in both classes that is the highest in the indicators exemplying, followed by indicators inferring, interpreting, comparing, and the lowest is in an indicator explaining.

Improved concept understanding of the students as a result of the implementation of the integration of STEM in LC $5 \mathrm{E}$ can be seen from the value $\mathrm{N}$-gain. The average score of $\mathrm{N}$-gain 0.09 experimental class is higher than the average score $\mathrm{N}$-gain class control, although both are in the same category. Where $\mathrm{N}$-gain experimental class 0.58 and $\mathrm{N}$-gain 0.49 control class. This is because the implementation of the integration of STEM in the experimental class. According Margen [14] that if N-gain of a higher learning from other learning, it can be said that the learning more effective.

This acquisition supports research Cylan that integrating STEM into LC 5E can improve student achievement. The results also support findings [8] that the integration of STEM learning can improve learning outcomes, increase motivation to learn, and increasing interest in STEM sains. This approach as proposed by Stohlmann [4] that the integration of STEM is one way to make learning connected and in accordance with the daily activities of students. "Learning this model the students are required to find their own concepts through various activities of the investigation conducted with the guidance of teachers. Starting from engagement activities, which is an early stage to explore the knowledge of students in the subject matter studied. At this stage teachers use technology products flashlight to be connected with a direct current electric concept based on everyday experience.

Of the seven aspects of the understanding according [7], there are five aspects that are expected to increase through the implementation of this model, namely: Exemplying, explaining, Inferring, interpreting and comparing. On learning scenarios planned by the researchers, explore phase is designed to instill the ability to interpreting, comparing, and inferring. In this phase, the teacher will give student problems and challenges contained in the worksheets that requires students to be able to interpret, compare and conclude. While on stage explain aspects drilled understanding of the concept is explained. While the elaborate stage is to compare, to exemply and to explain.

$\mathrm{N}$-gain for each indicator understanding showed an improvement in all aspects. Each improvement is in the aspect exemplying (0.88), followed by aspects inferring (0.72), interpreting (0.56), comparing $(0,51)$ and the smallest increase was in explaining aspects of $(0.31)$. This model can be derived from the theory, or based on research or experience.

A complete explanation includes the process of creating a causal model, which includes every major part in a system or any important event in the series of events, and the process of using the model to determine a change in one part of the system or relationship in the circuit affected by changes in other sections.

Achievement of an average $\mathrm{N}$-gain on this aspect is at the low category, due to the lack of provision of student experience in communicating the knowledge gained to the various forms of communication in the learning process both as outlined in worksheets, which should occur later explain or during the presentation. 


\section{CONCLUSIONS}

Research has shown that improving concept understanding. Students who taught LC 5E with STEM significantly different than students who taught LC 5E without STEM.

\section{References}

[1] National Research Council. Succsesfull K-12 STEM Education, Identify Efective Approaches In STEM. Washington,DC : The National Academyes Press. 2011.

[2] WS.Winkel. Psikologi Pengajaran. Jakarta : Gamedia. 1991.

[3] R. Bybee. The Case For STEM Education Challenges and Opportunity, NSTA, pp 1-130. 2013.

[4] Stohlmann, et al. Consideration For Teaching Integrating STEM Education. Journal of College Science Teaching. 2012.

[5] Rustaman. dkk. Strategi Belajar Mengajar Biologi. Malang: Penebit UNM. 2005.

[6] B. Benyamin, Taxonomy of Educational Objektif, Handbook 7, Kognative Domain, Longman. New York. 2003.
[7] Anderson, L. W., et al, A Taxonomy for Learning, Teaching, and Assessing. Longman. New York. 2001.

[8] Nugent, G. Extending Engeneering Education to K-12. The Teaching Technology Journal (6) 7. 2010.

[9] Morrison, J. TIES STEM Education Monograph Series, Attribute of STEM Education. Baltimore, MD: TIES. 2006.

[10] Clen, D . 5 E Model Use For elementary STEM Education. Maryland : Maryland Departement Education. 2011

[11] Ceylan, S. Improving A Sample Lesson Plan For Secondary Within The STEM Education (By Model 5E). Journal : Science Direct. 2014.

[12] Dass, P. Teaching STEM Effectively With The Learning Cycle Approach Journal K-12 STEM Education vol 1 Jan-Maret 201.5. 2015.

[13] Rahma, I. at all. First Implementation of STEM education Challenge In Indonesia. Laporan Penelitian. Bandung : UPI. 2014

[14] Margen at all The effectiveness of problem-based instruction: A comparative study of instructional methods and students characteristics. The interdisciplinary Journal of Problem-based Learning, Vol.1, No.2. 2006 